\title{
A Review on Vinasse A By-Product from Sugarcane Industry
}

\author{
Abdallah S Elgharbawy* \\ Materials Science Department, Institute of Graduate Studies and Research (IGSR), Alexandria University, Egypt
}

\begin{abstract}
The industries of sugar-alcohol production produce enormous quantities of agro-industrial wastes. The most important waste is vinasse, which is an aqueous stream of the distillation unit in the alcohol industry. The large quantities of vinasse cause harmful environmental pollution.
\end{abstract}

Keywords: Vinasse, Ethanol, Sugarcane

\section{Introduction}

The stream harms the environment owing to the enormous quantities that causes pollution. The amount of vinasse generated relies on the processing method applied and on the wine composition since it ranges between 10 and 18 liters of vinasse per liter of alcohol generated. ${ }^{1}$ Vinasse is produced from three sugary components: molasses, mixed must, and juice; it is a dilute solution. However, vinasse can be concentrated by evaporation to produce a product with a high value. ${ }^{2,3}$

Organic matter such as potassium, calcium, and magnesium are the most important chemical components of vinasse. Potassium is the most crucial element used for the agricultural usage. Consequently, vinasse is considered a source of food, organic matter, and water and increases the productivity of sugarcane with impacts on the chemical, physical and biological soil characteristics. ${ }^{4}$ But, the quantity of vinasse used in the agriculture industry should follow the proper procedures, which vary as per the soil properties. ${ }^{1}$ In addition, the high concentration of organic compounds in vinasse leads to a considerable environmental pollution. ${ }^{2,3}$

\section{The Pollution of Vinasse}

The use of vinasse causes soil and subterranean pollution. Vinasse characteristics that make pollution, contains high amount of oxygen (CRO) and biological needs for oxygen (BRO) rates, an acidic $\mathrm{pH}$. It also increases the temperature during production, and causes the corrosion. Frequent uses of high vinasse amounts contribute to a raise in nitrogen and potassium content in the soil that are the dominant chemical ingredients of vinasse. ${ }^{5,6}$ Vinasse accelerates soil deterioration such as improved compilation. However, this culminates in high water intrusion, clogging of mineral ingredients, and groundwater pollution. . $^{3,7}$

Some researchers studied the effect of the raw material and treated vinasse (an anaerobically-aerobically treatment performed in the existence and absence of oxygen to remove dissolved organic compound) on soil chemical properties. They found that untreated vinasse increased the soil salinity and contamination via zinc and manganese compounds. ${ }^{8}$

Some studies revealed that using vinasse residues affected

\begin{tabular}{|l|l|}
\hline \hline Quick Response Code: & *Corresponding author: Abdallah S Elgharbawy, 163 Horrya Avenue, P.O. Box 832, Shatby, \\
21526 Alexandria, Egypt \\
Received: 03 August, 2021 \\
Citation: Elgharbawy AS. A Review on Vinasse A By-Product from Sugarcane Industry. Trends \\
Petro Eng. 2021;1(2):1-3. DOI: 10.53902/TPE.2021.01.000506
\end{tabular}


water quality and causes harmful environmental influences. The effects of vinasse might be decreased using biological aerobic and anaerobic treatment that eliminate organic compounds, nitrate compounds, and dissolved solids. ${ }^{3}$ The effect of vinasse that contains amounts of heavy metals has no effect on the soil as there is little risk of soil contamination with these elements. ${ }^{9}$

\section{Vinasse Impact on the Soil}

Vinasse is used in the sugarcane watering enhancing the chemical, physical, and biological properties of soil. Many studies in Brazil reveals the crucial impacts of vinasse uses on the chemical and physical properties of soil. ${ }^{10}$ High contents of potassium, Calcium, and Magnesium improve soil macro-aggregation. A good improvement of the radicular system in sugarcane has been noticed after the vinasse application. ${ }^{9}$ The vinasse impacts on the sugarcane application in Brazil were investigated over 10 years. It was found that macro-nutrients were very abundant in the soil profile, but micronutrient availability was decreased., ${ }^{2,9}$

Different soil types were studied before and after vinasse application. It was noticed that the residue raised the $\mathrm{pH}$ and potassium content and it varies as per the soil species. It is also confirmed that there is an increase in potassium and organic carbon contents when investigating the chemical properties of the vinasse-treated soils used for sugarcane production. Consequently, if vinasse is a crucial resource of potassium, its use may lessen the requirement for inorganic potassium fertilizers. ${ }^{11}$ The impacts of continuous application of vinasse on the chemical and physical soil properties were studied in China. It was found that there is a reduction in soil density, increase in capillary porosity, and more increase in potassium content. ${ }^{7}$

The frequent application of the vinasse improves the growth and productivity of sugarcane. Another report from the same country concluded that vinasse used as a fertilizer increases soil fertility in sugar cane production systems. ${ }^{4}$ Another study in China on the vinasse from sugar beets revealed an increase in the concentrations of soil organic matter and nitrogen and an increase in soil cation exchange capacity.

Researchers in Greece studied the impacts of adding vinasse on the physical and chemical properties of soils that is used for wheat production. They concluded that the vinasse application leaded to an increase in nontoxic-potassium and sodium content in soil. To sum up, it can be concluded that agricultural utilization of vinasse contributes to many improvements in the soil quality with consequent benefits for crop productivity. ${ }^{9,12}$

\section{The Possible Forms of Vinasse Disposal}

1. Anaerobic digestion, using methanogenic bacteria, for the production of biogas, process (anaerobic digestion).

2. Vinasse concentration by evaporation, for return to farm as fertilizer.
3. Vinasse concentration by evaporation for combustion aiming at energy recovery.

4. Vinasse for high quality feed to microalgae for biodiesel production.

\section{Vinasse as fuel}

Vinasse can be used as fuel for the steam boilers that produces electricity that could allow mills to exploit bagasse burning for another application. ${ }^{13}$ Bio-methane is used as a fuel for vehicles such as tractors and semi-trucks in Brazil that use natural gas as a fuel. ${ }^{6,14}$ Concentrated vinasse will leak deeply into the soil to allow a lighter application of the product (Figure 1). ${ }^{1,11}$

\section{Path to biodiesel}

Vinasse produced in the distillery is transformed into biomass by algae

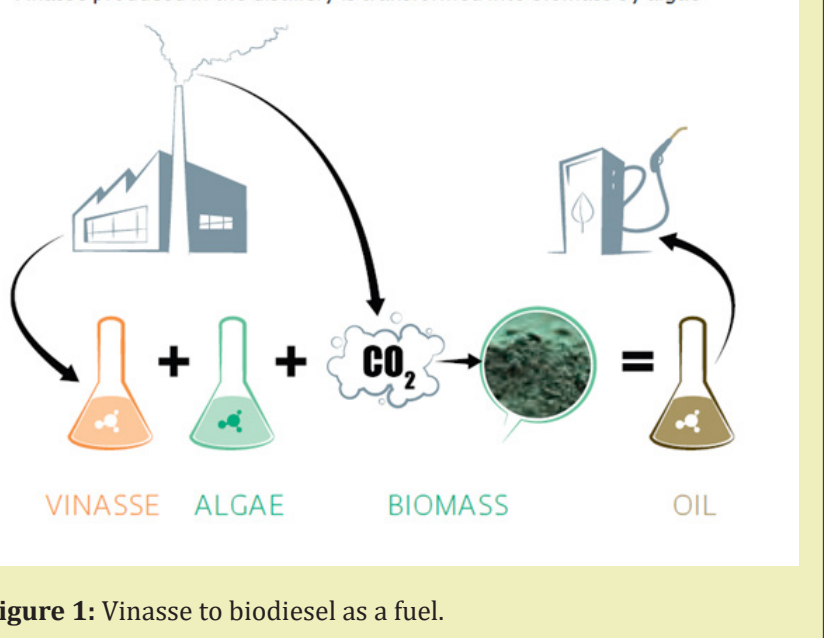

\section{Vinasse as animal food}

Some researchers developed a way to change the structural vinasse content to be used as a feedstock for animals as it contains a nutrient component. It shows diagram of the production process using both the organic and inorganic components of vinasse to produce high quality fish feed and oils, applying the zero-waste concept. Both vinasse and sugar contain a low content of sugar and consumed as nutrient for animals. ${ }^{5}$ However, the protein concertation in vinasse is extremely higher than in molasses. However, it is difficult to use the vinasse as a food for animal because of the high content of potassium. ${ }^{3,12}$

\section{Conclusion}

Vinasse is the final side product of biomass distillation and it is produced mainly from ethanol production from sugar and starch crops or cellulosic material. It consists of $93 \%$ water and $7 \%$ of solid. Vinasse is a harmful by-product of sugarcane industry but it can be valuable product if it converted to food or fuel. A few studies were revealed to investigate the recycling of vinasse. Therefore, many researches are required to investigate the importance of vinasse. 


\section{Acknowledgments}

None.

\section{Funding}

None.

\section{Conflicts of Interest}

Author declares that there is no conflict of interest.

\section{References}

1. Christofoletti CA, Escher JP, Correia JE, et al. Sugarcane vinasse: environmental implications of its use. Waste Manag. 2013;33(12):27522761.

2. Parsaee M, MKD Kiani, Karimi K. A review of biogas production from sugarcane vinasse. Biomass and Bioenergy. 2019;122:117-125.

3. Vlyssides A, Israilides $\mathrm{C}$, Loizidou $\mathrm{M}$, et al. Electrochemical treatment of vinasse from beet molasses. Water Science and Technology. 1997;36(2-3):271-288.

4. Cerri BC, Borelli LM, Stelutti IM, et al. Evaluation of new environmental friendly particulate soil fertilizers based on agroindustry wastes biopolymers and sugarcane vinasse. Waste Management. 2020;108:144-153.

5. Abdallah SE. A Review on Phthalic Anhydride Industry and Uses. Trends Petro Eng. 2021;1(1):1-2.000505.

6. El-gharbawy A, Sadik W, Sadek O, et al. A review on biodiesel feed- stocks and production technologies. Journal of the Chilean Chemical Society. 2021;66(1):5098-109.

7. Elgharbawy AS, Sadik WA, Sadek OM. Maximizing biodiesel production from high free fatty acids feedstocks through glycerolysis treatment. Biomass and Bioenergy. 2021;146:105997.

8. Elgharbawy A, Sayed A. A review on natural gas previous, current and forecasting prices and demand. Journal of Petroleum and Mining Engineering. 2020;22(1):61-64.

9. Fuess LT, Rodrigues IJ, Garcia ML. Fertirrigation with sugarcane vinasse: Foreseeing potential impacts on soil and water resources through vinasse characterization. J Environ Sci Health A Tox Hazard Subst Environ Eng. 2017;52(11):1063-1072.

10. García-Depraect 0 , Muñoz R, van Lier JB, et al. Three-stage process for tequila vinasse valorization through sequential lactate, biohydrogen and methane production. Bioresour Technol. 2020;307:123160.

11. Buller LS, Romero CWDS, Lamparelli RAC, et al. A spatially explicit assessment of sugarcane vinasse as a sustainable by-product. Sci Total Environ. 2021;765:142717.

12. Silva AFR, Magalhães NC, Cunha PVM, et al. Influence of COD/SO42ratio on vinasse treatment performance by two-stage anaerobic membrane bioreactor. J Environ Manage. 2020;259:110034.

13. Ahmed Elgharbawy A, Sadik W, Sadek O, et al. Transesterification reaction conditions and low-quality feedstock treatment processes for biodiesel production- A review. Journal of Petroleum and Mining Engineering. 2021; p. 98-103.

14. Elgharbawy AS. Performing a risk analysis study for implementing a biodiesel plant. Plant Pet Chem Eng J. 2021;5(1):000248. 